\title{
The association between cerebral amyloid angiopathy and atherosclerosis in patients with intracerebral hemorrhages
}

\author{
Tadeusz Andrzej Mendel ${ }^{1}$, Teresa Wierzba-Bobrowicz ${ }^{2}$, Tomasz Stępieñ ${ }^{2}$, Grażyna Maria Szpak ${ }^{2}$ \\ ${ }^{1} 2^{\text {nd }}$ Department of Neurology, Institute of Psychiatry and Neurology, Warsaw, ${ }^{2}$ Department of Neuropathology, Institute Psychiatry \\ and Neurology, Warsaw, Poland
}

\begin{abstract}
Aim of the study: To analyze the incidence and grade of cerebral amyloid angiopathy (CAA) and atherosclerosis (AS) in cerebral vessels in patients who died from spontaneous intracerebral hemorrhage.

Material and methods: The clinical diagnosis, based on CT scans of the brain, was made and immunohistochemic neuropathological examinations were performed in patients with intracerebral hemorrhages due to CAA. Cerebral amyloid angiopathy was diagnosed according to the Boston criteria. The Vonsattel and Mountoy scales were used to assess the grade and score of CAA. Atherosclerosis was assessed according to a four-grade scale presented in the Coding Guide from Collaborative Study of Epidemiological Factors in Cerebral Vascular Disease.

Results: Of the 189 patients who died due to intracerebral hemorrhages 42 (22\%) presented CAA. According to the Vonsattel scale this group comprised $32(76 \%)$ patients who showed severe, $6(14 \%)$ moderate and $4(10 \%)$ mild CAA. Atherosclerosis was diagnosed in the CAA group of patients as follows: 6 (14\%) with grade 1; 20 (49\%) with grade 2; 9 (20\%) with grade 3; and 7 (17\%) patients with grade 4.

Conclusions: There was no correlation between CAA and AS. The CAA was probably the direct cause of death in part of cases with advanced CAA. The different mechanisms presumably can cause CAA and AS.
\end{abstract}

Key words: cerebral amyloid angiopathy, CAA, $\beta$-amyloid, atherosclerosis, AS, intracerebral hemorrhage, ICH.

\section{Introduction}

Intracerebral haemorrhage $(\mathrm{ICH})$ can be caused by cerebral amyloid angiopathy (CAA) and by atherosclerosis (AS). Cerebral amyloid angiopathy is a disease that occurs mostly in older people in whom deposits of amyloid in the vessel walls of small- and medium-size leptomeningeal, cortical arteries, arterioles and veins can be presented $[1,2,15,23]$. Cerebral amyloid angiopathy is the second cause of brain haemorrhage after atherosclerosis. It can also induce ischemic strokes, transient ischemic attacks, leukoencephalopathy and amyloidoma like tumour. Cerebral amyloid angiopathy can coexist with many dementia-inducing disorders, such as Alzheimer's disease (AD), dementia with Lewy bodies, Down syndrome and others $[3,4,8,9,16,18,21,22,29,31,33]$. In cerebral amyloid angiopathy, intracerebral haemorrhages are superficial, multiple, lobar and occur in older people mostly with no history of hypertension $[14,20,25]$. In patients with atherosclerosis, $\mathrm{ICH}$ occurs mostly as 
single foci. The prevalence of CAA in intracerebral haemorrhages can reach $30 \%$ [9]. It is found that the occurrence of both CAA and AS increases in older groups of patients. In large vessels, atherosclerosis occurs, but hypertension and CAA can cause pathology in small vessels $[14,20,25]$. Authors were interested in studying the convergence, degree and severity of changes in both kinds of vessels.

\section{Aim of the study}

The aim of the study was to assess the incidence of CAA in patients with intracerebral haemorrhage and to find out how often atherosclerosis is presented. Our aim was to compare the occurrence of the CAA with atherosclerosis to confirm the hypothesis that these diseases are induced by different mechanisms. We were also trying to analyse the correlation between these two processes.

\section{Material and methods}

Patients with suspected ICH were admitted to the $2^{\text {nd }}$ Department of Neurology of the Institute of Psychiatry and Neurology, Warsaw, Poland. They were hospitalized in the Stroke Unit. Of the 189 patients who died due to spontaneous intracerebral haemorrhage in 1993-2012, CAA was diagnosed postmortem in $42(22 \%)$ patients. There were $34(81 \%)$ women and $8(19 \%)$ men who died from intracerebral haemorrhage caused by CAA. Their age ranged from 54 to 97 years (mean $79.90 \pm 8.07$ years).

The final diagnosis was made during an autopsy after histological and immunohistological examinations. Patients with brain aneurysm, arteriovenous malformation, brain tumour, venous thrombosis, haemophilias, past head injury as well as those on anticoagulants and under thrombolytic therapy were excluded.

The most advanced CAA lesions in each patient were analysed.

Statistical analyses were carried out using the $\chi^{2}$ test. Statistical analysis was performed with Stat 10.0. Statistical significance was set at $p<0.05$.

\section{Neuropathological assessment}

The autopsy was performed according to the standard protocol. The brain was fixed in $4 \%$ paraformaldehyde in $0.1 \mathrm{M}$ phosphorane-buffer saline and embedded in paraffin. Then, it was sliced coronally. The specimens were stained with H\&E, PAS, Congo red and immunohistochemically with two antibodies: anti A $\beta$ 8-17 (DAKO, 1 : 50), actin (SMA, DAKO, $1: 50)$. Under microscopic evaluation the brain was considered positive for CAA when it showed at least one leptomeningeal or cortical congophilic vessel with yellow-green birefringence under polarized light. The severity of CAA was classified according to the Vonsattel scale as follows:

1. Mild. $\beta$-amyloid is restricted to a Congophilic rim around normal or atrophic smooth muscle fibers (which might be absent), leaving an optically empty tiny vacuole-like zone surrounded by amyloid in media of otherwise normal vessels.

2. Moderate. Media is replaced by $\beta$-amyloid and thicker than normal, with no evidence of remote or recent blood leakage.

3. Severe. There is extensive $\beta$-amyloid deposition with focal wall fragmentation and at least one focus of perivascular leakage evidenced by the presence of erythrocytes or hemosiderin or both [35].

The estimated proportion of $\beta$-amyloid involvement in each vessel was recorded on the 0-4 Mountjoy scale. A score of 0 indicated the absence of amyloid; a score of 1 , involvement of up to one-quarter of the vessel circumference; a score of 2, involvement of up to one-half of the vessel circumference; a score of 3 , involvement of up to three-quarters of the vessel circumference; a score of 4 indicated total involvement of the vessel [24].

Atherosclerosis was classified according to a 4-grade scale [5]. Grade 1, opacity to very thin plaque, involving only a small part of the vessel circumference with no lumen narrowing; Grade 2, thin plaque, involving over half of the vessel circumference with minimal lumen narrowing or small thick plaque, which produces less than $25 \%$ of lumen narrowing; Grade 3, thin plaque, involving the entire circumference with mild lumen narrowing. Localized plaque producing $25 \%$ to $50 \%$ of lumen narrowing; Grade 4, very thick plaque, involving the entire circumference with moderate to marked narrowing. Localized plaque resulting in over $50 \%$ of lumen narrowing [5]. The occurrence and severity of AS were assessed in the vessels in the circle of Willis $[10,19,35]$.

\section{Results}

Deposits of $\beta$-amyloid in CAA were observed in all kinds (cortical and meningeal) of cerebral vessels: arteries, capillaries and veins $[23,24]$.

Of the 189 patients who died due to intracerebral haemorrhages, 42 (22\%) patients presented CAA. 
Table I. Cerebral amyloid angiopathy and atherosclerosis severity in cerebral vessels in patients with intracerebral haemorrhages

\begin{tabular}{|c|c|c|c|c|c|}
\hline Number/Initials & Age & Sex & $\begin{array}{l}\text { CAA severity according } \\
\text { to the Vonsattel scale }\end{array}$ & $\begin{array}{l}\text { CAA severity according } \\
\text { to the Mountjoy scale }\end{array}$ & $\begin{array}{l}\text { Atherosclerosis } \\
\text { grade }\end{array}$ \\
\hline $1 / J F D$ & 71 & $\mathrm{~F}$ & 1 & 3 & 2 \\
\hline $2 / \mathrm{WP}$ & 84 & $\mathrm{~F}$ & 3 & 4 & 1 \\
\hline 3/ZD & 75 & $\mathrm{~F}$ & 2 & 4 & 3 \\
\hline $4 / A C$ & 82 & $\mathrm{~F}$ & 3 & 4 & 2 \\
\hline 5/WP & 85 & $\mathrm{~F}$ & 3 & 4 & 4 \\
\hline 6/JW & 73 & $\mathrm{~F}$ & 3 & 4 & 4 \\
\hline 7/JW & 83 & M & 3 & 4 & 2 \\
\hline 8/RZ & 87 & $\mathrm{~F}$ & 2 & 4 & 2 \\
\hline 9/AP & 83 & $\mathrm{~F}$ & 3 & 4 & 1 \\
\hline 10/KT & 97 & $\mathrm{~F}$ & 3 & 4 & 4 \\
\hline 11/Mt & 80 & $\mathrm{~F}$ & 1 & 3 & 3 \\
\hline $12 / \mathrm{BP}$ & 68 & $\mathrm{~F}$ & 3 & 4 & 1 \\
\hline 13/HW & 72 & $\mathrm{~F}$ & 3 & 4 & 1 \\
\hline 14/TN & 89 & M & 3 & 4 & 1 \\
\hline 15/DK & 80 & $\mathrm{~F}$ & 3 & 4 & 1 \\
\hline $16 / S P$ & 68 & M & 3 & 4 & 2 \\
\hline 17/ZO & 89 & $\mathrm{~F}$ & 3 & 4 & 2 \\
\hline 18/RB & 77 & $\mathrm{~F}$ & 3 & 4 & 3 \\
\hline $19 / \mathrm{SD}$ & 84 & $\mathrm{~F}$ & 3 & 4 & 2 \\
\hline 20/AP & 87 & $\mathrm{~F}$ & 3 & 4 & 2 \\
\hline 21/AWZ & 72 & $\mathrm{~F}$ & 3 & 4 & 4 \\
\hline 22/EC & 89 & M & 3 & 4 & 2 \\
\hline 23/PW & 54 & $\mathrm{~F}$ & 3 & 4 & 3 \\
\hline $24 / 50$ & 78 & $\mathrm{~F}$ & 3 & 4 & 3 \\
\hline $25 / J Z$ & 85 & $M$ & 3 & 4 & 4 \\
\hline 26/TF & 82 & $M$ & 2 & 3 & 4 \\
\hline $27 / A G$ & 89 & $\mathrm{~F}$ & 2 & 4 & 3 \\
\hline 28/MK & 82 & $\mathrm{~F}$ & 3 & 4 & 3 \\
\hline 29/AO & 77 & $\mathrm{~F}$ & 3 & 4 & 2 \\
\hline $30 / \mathrm{RS}$ & 79 & $\mathrm{~F}$ & 3 & 4 & 2 \\
\hline $31 / M S G$ & 79 & $\mathrm{~F}$ & 3 & 4 & 2 \\
\hline $32 / J F$ & 81 & $\mathrm{~F}$ & 3 & 4 & 2 \\
\hline $33 / \mathrm{HK}$ & 79 & $\mathrm{~F}$ & 3 & 4 & 3 \\
\hline $34 / M M$ & 75 & $\mathrm{~F}$ & 3 & 4 & 2 \\
\hline 35/EK & 67 & $\mathrm{~F}$ & 2 & 4 & 4 \\
\hline $36 / S Z$ & 91 & $\mathrm{~F}$ & 3 & 4 & 3 \\
\hline 37/JP & 88 & $\mathrm{~F}$ & 3 & 4 & 2 \\
\hline $38 / \mathrm{HG}$ & 71 & $M$ & 3 & 4 & 2 \\
\hline 39/AR & 84 & $\mathrm{~F}$ & 1 & 4 & 2 \\
\hline $40 / K M$ & 77 & $\mathrm{~F}$ & 3 & 4 & 2 \\
\hline 41/WR & 88 & $\mathrm{~F}$ & 2 & 4 & 2 \\
\hline $42 / Z N$ & 75 & $\mathrm{~F}$ & 1 & 4 & 2 \\
\hline
\end{tabular}

CAA - cerebral amyloid angiopathy 
Table II. Frequency of cerebral amyloid angiopathy by age groups

\begin{tabular}{|lcc|}
\hline Age (Decades) & Number $(\%)$ & Number $(\%)$ \\
\hline $50-60$ & $1(2 \%)$ & $1(2 \%)$ \\
\hline $61-70$ & $3(7 \%)$ & $3(7 \%)$ \\
\hline $71-80$ & $17(41 \%)$ & \\
\hline $81-90$ & $19(45 \%)$ & $36(86 \%)$ \\
\hline $91-100$ & $2(5 \%)$ & $2(5 \%)$ \\
\hline
\end{tabular}

The CAA group consisted of 34 (81\%) women and $8(19 \%)$ men. The age in the whole group ranged from 54 to 97 years (mean $79.90 \pm 8.07$ years) (Table I), but in the 71-90 age group there were as many as $36(86 \%)$ cases (Table II).

Vessels with $\beta$-amyloid were found in 42 (22\%) patients. All stages of CAA in vessels were found in the study group. The grades of CAA according to the Vonsattel scale are presented in Table I [36]. Mild CAA was found in 4 (10\%) patients, moderate in $6(14 \%)$ and severe in 32 (76\%) patients (Table III). The estimated proportion of amyloid involvement of vessels was recorded on the Mountjoy scale of 0-4 grades [24]. There were no patients with grades 1 and 2; 3 (5\%) patients were rated 3 grade and 39 (95\%) patients 4 grade (Table IV).

Atherosclerosis was assessed according to a fourgrade scale [5]. This included 6 (14\%) patients diagnosed with grade 1, 20 (49\%) with grade 2, 9 (20\%) with grade 3 , and 7 (17\%) patients with grade 4 (Tables
III and IV). Only in 5 (12\%) patients, the advanced atherosclerotic changes were concomitant with advanced CAA.

There was a tendency but not a statistical significant difference between advanced CAA according to Vonsattel scale in 32 (76\%) patients and small atherosclerosis in $26(63 \%)$ cases ( $p<0.57)$.

The Mountjoy scale was not used for the final statistical assessment, because nearly all of patients 39 (95\%) of the analysed group had grade 4 , which indicated the total involvement of the vessel.

\section{Discussion}

Neuropathological examination is still a "gold standard" for CAA diagnosis, because only postmortem examination can set the definite diagnosis of CAA. Using the Boston criteria for diagnosis of CAA and having CT and/or MRI scans, the neurologist may select those of the patients who are most suspected of having CAA $[2,3,9,12,17,26]$.

There is a lot of diagnostic tools, which can be used in diagnosis of CAA during intracerebral haemorrhage, but only the neuropathological examination can confirm the presence of this disease and reveal individual stages of CAA, kinds of vessels involved in this process and classify the grade of CAA and its localization $[30,36]$.

The damaged vessels in CAA and AS showed a different morphological picture. There are different kinds of pathology in these two processes. In large vessels,

Table III. Correlation between $\beta$-amyloid grade in brain vessels according to the Vonsattel scale and atherosclerosis grade in cerebral vessels

\begin{tabular}{|lccc|}
\hline $\begin{array}{l}\beta \text {-amyloid grade in brain vessels according to } \\
\text { the Vonsattel scale }\end{array}$ & $\begin{array}{c}\text { Number } \\
(\%)\end{array}$ & $\begin{array}{c}\text { Atherosclerosis grade in brain vessels } \\
(\%)\end{array}$ & $\begin{array}{c}\text { Number } \\
(\%)\end{array}$ \\
\hline 1 & $4(10 \%)$ & 1 & $6(14 \%)$ \\
\hline 2 & $6(14 \%)$ & 2 & $(49 \%)$ \\
\hline 3 & $32(76 \%)$ & 3 & $9(20 \%)$ \\
\cline { 2 - 4 } & & 4 & $7(17 \%)$ \\
\hline
\end{tabular}

Table IV. Correlation between the grade of $\beta$-amyloid changes in brain vessels according to the Mountjoy scale and atherosclerosis grade in cerebral vessels

\begin{tabular}{|lccc|}
\hline $\begin{array}{l}\beta \text {-amyloid grade in brain vessels according to } \\
\text { the Mountjoy scale }\end{array}$ & $\begin{array}{c}\text { Number } \\
(\%)\end{array}$ & $\begin{array}{l}\text { Atherosclerosis grade in brain vessels } \\
(\%)\end{array}$ \\
\hline 1 & 0 & 1 & $6(14 \%)$ \\
\hline 2 & 0 & 2 & $(49 \%)$ \\
\hline 3 & $3(5 \%)$ & 3 & $9(20 \%)$ \\
\hline 4 & $39(95 \%)$ & 4 & $7(17 \%)$ \\
\hline
\end{tabular}


atherosclerotic plaques, hyalinization, thickening, narrowing and stiffness of the wall are observed. Small vessels are mostly involved in dementia and Alzheimer's disease [6,32,34].

In CAA, haemorrhages are mainly lobar and multiple while in hypertension and atherosclerosis they are single and in deep structures [14,20,25].

Atherosclerosis is a disease of arterial intima membrane due to the loss of smooth muscle cells and damage to elastic fibres. Atherosclerosis is by far the leading systemic vasculopathy to result in brain infarcts, especially in older patients. Atherosclerosis can affect both large intracranial and extracranial arteries, and may extend into leptomeningeal arteries [6].

Intracranial atherosclerosis is most severe in major branches of the circle of Willis and vertebrobasilar system. The extent and topography of atherosclerosis in the basal vessels are often best documented by removing the circle of Willis from the fixed brain [6]. In this publication the authors have decided to compare atherosclerosis localized in the circle of Willis with CAA localized in cortical and meningeal vessels.

The aim of our study was to assess the incidence of CAA and its correlation with atherosclerosis in a group of patients who died due to intracerebral haemorrhage. In Poland, such an analysis has not as yet been carried out. The autopsy was performed in about $70 \%$ of all the patients who died during hospitalization in our department during the years 19932012. Nowadays, such a high percent of autopsies is not so frequent in other countries.

Cerebral amyloid angiopathy is mostly observed as a periventricular leucoencephalopathy, ischemic changes, haemorrhage and it occurs with concomitant dementia $[3,4,9]$. In our study group, CAA was observed more often in women than in men (34 vs. 8). We suppose that men died due to other causes, mainly due to haemorrhage caused by hypertension at an earlier age, when amyloid changes were not yet formed. In older patients, CAA was the cause of lobar haemorrhagic stroke, but in a younger group, haemorrhagic foci were localized in basal ganglia mainly as a cause of hypertension.

According to the Vonsattel and Mountjoy scales, severe and moderate changes predominated in our group of patients (Tables III and IV). These observations are consistent with other authors in the older group of patients with CAA $[15,26,33,36]$.
Atherosclerotic plaques are prone to rupture with subsequent thrombus. The thrombus resulting from plaque rupture can either lead to vascular occlusion or produce the embolus and occlusion of a smaller artery. Atherosclerotic aneurysm is a consequence of cerebral vessel walls destruction, rarely leading to subsequent rupture and haemorrhage [10].

Atherosclerosis and age-related changes may impede the perivascular drainage of $\beta$-amyloid as pre-existing CAA does [11,37]. Atherosclerosis concerns mostly the large and middle-sized vessels, but CAA is localized mostly in middle-sized and small vessels and capillaries [6].

Many scientists have been searching for the correlation between CAA and atherosclerosis [7,13,32]. Okazaki et al. (1979) found no correlation between the severity of CAA and AS [26]. On the other hand, Roher et al. (2011) found that occlusions of the circle of Willis arteries were more extensive in Alzheimer's disease group than in non-demented group. Based on their results, combined with the consideration of multifaceted effects of impaired cerebral circulation, they suggest an immediate need for prospective clinical trials to assess the efficacy of AD prevention using anti-atherosclerotic agents [28].

In the study group, we observed the reverse proportion between the level of CAA and atherosclerosis which was not statistically significant. These observations allowed us to suggest the thesis that there are different mechanisms causing CAA and atherosclerosis and that are two different groups of patients $[27,32,34,38]$.

\section{Conclusions}

1. There was no correlation between CAA and AS.

2. The CAA was probably the direct cause of death in some cases with advanced CAA.

3. The different mechanisms presumably can cause CAA and AS.

\section{References}

1. Aho L, Jolkkonen J, Alafuzoff I. $\beta$-amyloid aggregation in human brains with cerebrovascular lesions. Stroke 2006; 37: 2940-2945.

2. Attems J. Sporadic cerebral amyloid angiopathy: pathology, clinical implications, and possible pathomechanisms. Acta Neuropathol 2005; 110: 345-359.

3. Biffi A, Greenberg SM. Cerebral amyloid angiopathy: a systematic review. J Clin Neurol 2011; 7: 1-9. 
4. Charidimou A, Gang Q, Werring DJ. Sporadic cerebral amyloid angiopathy revisited: recent insights into pathophysiology and clinical spectrum. J Neurol Neurosurg Psychiatry 2012; 83: 124-137.

5. Collaborative Study of Epidemiological Factors in Cerebral Vas cular Disease. Coding Guide. Under the auspices of World Federation of Neurology and The National Institute of Neurological Diseases and Blindness United States Public Health Service. Antwerp, 1959.

6. Ellison D, Love S, Chimelli LMC, Harding B, Lowe JS, Vinters HV Brandner S, Yong WH. Neuropathology, a reference text of CNS pathology. Mosby, Edinburgh 2013.

7. Felwick R, Amar K. A case of cerebral amyloid angiopathy. Med Sci Monit 2007; 13: 24-26.

8. Fereiro JA, Ansbacher LE, Vinters HV. Stroke related to cerebral amyloid angiopathy: the significance of systemic vascular dis ease. J Neurol 1989; 236: 267-272.

9. Greenberg SM. Cerebral amyloid angiopathy: Prospects for clin ical diagnosis and treatment. Neurology 1998; 51: 690-694.

10. Grinberg LT, Thal DR. Vascular pathology in the aged human brain. Acta Neuropathol 2010; 119: 277-290.

11. Hawkes CA, Härting W, Kacza J, Schliebs R, Weller RO, Nicoll JA, Carrare RO. Perivascular drainage of solutes is impaired in the aging mouse brain and in the presence of cerebral amyloid angiopathy. Acta Neuropathol 2011; 121: 431-443.

12. Hendricks HT, Franke CL, Theunissen PH. Cerebral amyloid angiopathy: diagnosis by MRI and brain biopsy. Neurology 1990; 40 1308-1310.

13. Honing LS, Kukull W, Mayeux R. Atherosclerosis and AD: Analysis of data from the US national Alzheimer's Coordinating Center. Neurology 2005; 64: 494-500.

14. Ishii N, Nishihara Y, Horie A. Amyloid angiopathy and lobar cerebral haemorrhage. J Neurol Neurosurg Psychiatry 1984; 47: 1203-1210.

15. Jellinger KA. Spatial distribution of hemorrhages in cerebral amyloid angiopathy. Ann Neurol 2006; 59: 1.

16. Karbowniczek A, Wierzba-Bobrowicz T, Mendel T, Nauman P. Cerebral amyloid angiopathy manifestated as a brain tumour. Clinical and neuropathological characteristics of two cases. Folia Neuropathol 2012; 50: 194-200.

17. Knudsen KA, Rosand J, Karluk D, Greenberg SM. Clinical diag nosis of cerebral amyloid angiopathy: validation of the Boston Criteria. Neurology 2001; 56: 537-539.

18. Lang EW, Ya ZR, Preul C, Hugo HH, Hempelmann RG, Buhl R, Barth $\mathrm{H}$, Klinge $\mathrm{H}$, Mehdorn HM. Stroke pattern interpretation: the variability of hypertensive versus amyloid angiopathy hemorrhage. Cerebrovasc Dis 2001; 12: 121-130.

19. Larinov S, Dedeck O, Birkenmeier G, Ornantes M, Ghebremed hin E, Thal DR. The intronic deletion polymorphism of the $\alpha 2$-macroglobulin gene modulates the severity and extent of atherosclerosis in the circle of Willis. Neuropathol App Neurobiol 2006; 32: 451-454.

20. Lopez JR, Fontanillo MMF, Carretero MJM, Garcia EC, Jaime DE, Montero JLM, Hermida MJP. Lobar intracerebral haemorrhage and cerebral amyloid angiopathy: analysis of a series of 106 patients. Neurologia 2009; 24: 386-390.
21. Mendel T, Bertrand E, Szpak GM, Stepień T, Wierzba-Bobrowicz T. Cerebral amyloid angiopathy as a cause of an extensive brain hemorrhage in adult patient with Down's syndrome a case report. Folia Neuropathol 2010; 48: 206-211.

22. Mendel T, Bertrand E, Szpak GM, Stępień T, Wierzba-Bobrowicz T. Complications of severe cerebral amyloid angiopathy in the course of dementia with Lewy bodies. A case report. Folia Neuropathol 2010; 48: 293-299.

23. Mendel T, Wierzba-Bobrowicz T, Stępień T, Szpak GM. Veins involvement by $\beta$-amyloid in intracerebral haemorrhage. Folia Neuropathol 2013; 51: 120-126.

24. Mountjoy CQ, Tomlinson BE, Gibson PH. Amyloid and senile plaques and cerebral blood vessels. J Neurol Sci 1982; 57: 89-103.

25. Oide T, Takahashi H, Yutani Ch, Ishihara T, Ikeda S. Relationship between lobar intracerebral hemorrhage and leukoencephalopathy associated with cerebral amyloid angiopathy: clinicopathological study of 64 Japanese patients. Amyloid 2003; 10 : 136-143.

26. Okazaki H, Reagan TJ, Campbell RJ. Clinicopathological studies of primary cerebral amyloid angiopathy. Mayo Clin Proc 1979; 54: 22-31.

27. Roher AE, Esh C, Rahman A, Kokjohn TA, Beach TG. Atherosclerosis of cerebral arteries in Alzheimer disease. Stroke 2004; 35 Suppl 1: 2623-2627.

28. Roher AE, Tyas SL, Maarouf CL, Drugs ID, Kokjohn TA, Emmerling MR, Garami Z, Belohlavek M, Sabbagh MN, Sue LI, Beach TG. Intracranial atherosclerosis as a contributing factor to Alzheimer's disease dementia. Alzheimer Dementia 2011; 7 : 436-444.

29. Rosand J, Muzikansky A, Kumar A, Wisco JJ, Smith EE, Berensky RA, Greenberg SM. Spatial clustering of hemorrhages in probable cerebral amyloid angiopathy. Ann Neurol 2005; 58 : 459-462.

30. Samandouras G, Teddy PJ, Cadoux-Hudson T, Ansorge O. Amyloid in neurosurgical and neurological practice. J Clin Neurosc 2006; 13: 159-167.

31. Szpak GM, Lewandowska E, Śliwińska A, Stępień T, Tarka S, Mendel T, Rafałowska J. Inflammatory cerebral amyloid angiopathy: the overlap of perivascular (PAN-like) with vasculitic (A $\beta$-related angiitis) form: an autopsy case. Folia Neuropathol 2011; 49: 335-347.

32. Thal DR, Ghebremedhin E, Orantes M, Wiestler OD. Vascular pathology in Alzheimer disease: correlation of cerebral amyloid angiopathy and arteriosclerosis/lipohyalinosis with cognitive decline. J Neuropathol Exp Neurol 2003; 62: 1287-1301.

33. Thanvi B, Robinson T. Sporadic cerebral amyloid angiopathy an important cause of cerebral haemorrhage in older people. Age Ageing 2006; 35: 565-571.

34. Tian J, Shi J, Bailey K, Mann DMA. Relationships between arteriosclerosis, cerebral amyloid angiopathy and myelin loss from cerebral cortical white matter in Alzheimer's disease. Neuropathol Appl Neurobiol 2004; 30: 46-56.

35. Vinters HV, Ellis WG, Zarow C, Zaias BW, Jagust WJ, Mack WJ, Chui HC. Neuropathologic substrates in ischemic vascular dementia. J Neurpathol Exp Neurol 2000; 59: 931-945. 
36. Vonsattel JPG, Myers RH, Hedley-Whyte ET, Ropper AH, Bird ED, Richardson EP. Cerebral amyloid angiopathy without and with cerebral hemorrhages: a comparative histological study. Ann Neurol 1991; 30: 637-649.

37. Weller RO, Boche D, Nicoll JAR. Microvasculature changes and cerebral amyloid angiopathy in Alzheimer's disease and their potential impact on therapy. Acta Neuropathol 2009; 118: 87-102.

38. Yamada M, Sodeyama N, Itoh Y, Otomo E, Matsusida M, Mizusawa $\mathrm{H}$. No association of paroxonase genotype or atherosclerosis with cerebral amyloid angiopathy. Stroke 2002; 33: 896-900. 